\title{
Organizational Culture and its Impact on Increasing the Quality of Banking Work
}

\author{
Aisha Abd Alla ALmahjob Jamal* \\ Department of Human Resources Management, Faculty of Business, \\ University of Jeddah, Kingdom of Saudi Arabia; aalmahjob@uj.edu.sa
}

\begin{abstract}
Background/Objectives: This study aims to identify the organizational culture and its impact on increasing the quality of banking performance, which is shown by the relationship between the cultures of the organization. Methods/Statistical Analysis: The method applied in this study encourages creativity and innovation, improving the quality of work and the influence of prevailing cultural values on increasing the quality of work. Findings: The results of the study show that there is an impact on the quality of work of the cultural values prevailing in the Organization, which have been achieved in the first place. And that there is a positive relationship between the culture of the organization that encourages creativity and innovation and improve the quality of work achieved secondly. Improvements/Applications: The study recommends the need to pay attention to the factors of organizational culture and develop them through training and motivation to innovate for their positive impact on the quality of banking work.
\end{abstract}

Keywords: Banking Working, Organizational Culture, Quality of Banking

\section{Introduction}

The theme of organizational culture has recently received considerable attention from the perspective of strategic management, organizational behavior, human resource management and sociology as one of the key determinants of the success and supremacy of business organizations, especially at present when the business environment is characterized by rapid. The organizations' performance and the achievement of their objectives; organizations that have an adaptive culture that enables their members to adhere to discipline, creativity and innovation, to participate in decision making, which leads them to achieve outstanding individual performance that enables the organization to achieve ${ }^{1}$.

The success of organizations in achieving their objectives requires the availability of several organizational variables, the most important of which is the improvement of employee behavior, which is reflected in the personality of the organization itself ${ }^{2}$. It is also a determinant of organizational behavior; it affects the satisfaction of employees and their level of performance. Improving employee behavior is one of the characteristics of the work environment, so creative individuals' behavior must be influenced by the prevailing organizational climate. It either encourages or impedes creativity. Improving employee behavior gives the opportunity for creative growth and encourages innovation and gives individuals greater scope for work, communication and decisionmaking., and provides material and moral incentives ${ }^{3}$. It is creative organizations that provide an appropriate regulatory environment in which innovation is rooted as a renewed institutional goal and make creativity a fundamental and vital task shared by all employees. It is the basis for their growth, existence and prosperity.

\section{Literature Survey}

There have been numerous studies on the quality of work and its association with organizational culture to see the impact of organizational culture on banking performance, including:

*Author for correspondence 
- $\mathrm{In}^{4}$ the study dealt with the reality of organizational culture, the reality of the administrative empowerment of women leaders in government ministries and also the relationship of this organizational culture to the administrative empowerment of women leaders. The results of the study showed a moderate organizational culture for women leaders and a positive relationship between organizational culture and empowerment. And that one of the most important obstacles to the empowerment of women leaders is the stagnation of the organizational culture that does not encourage the adoption of new ideas and the fear of the presidents of their positions and positions of employment.

- $\operatorname{In}^{5}$ the study dealt with the role of the culture of the institution in improving the performance of human resources in economic institutions. The study concluded that the level of the institution's culture in the institution in question was average, and that there is a statistically significant impact on the culture of the institution in improving the performance of human resources in the institution in question.

- $\operatorname{In}^{6}$ the study examined the impact of organizational culture on the performance of human resources in a sample of small and medium enterprises. The results of the study showed that the prevailing organizational culture affects the performance of human resources in small and medium enterprises in the state of Ouargla, so that participation in decision making as well as commitment and respect for time affect the performance of human resources. The creativity and innovation in the organization have a clear impact on performance; the spirit of the team does not affect the performance of human resources in the studied SMEs.

- $\operatorname{In}^{7}$ the aim of the study was to know the availability and adoption of the study sample for organizational culture and how to use it to enhance the level of organizational commitment and determine the correlation between organizational culture and its dimensions and organizational commitment and dimensions. And determine the relationship of the impact between the organizational culture and its dimensions and organizational commitment. The results of the study showed that there is a significant correlation between the organizational culture and the organizational commitment, and it showed that there is a significant effect of the organizational culture on the organizational commitment. The study emphasized the importance of organizational culture and organizational commitment, which necessitates adopting culture as a contemporary input to enhance organizational commitment.

- $\mathrm{In}^{8}$ the study aimed to know the role of the regulatory commitment in improving the performance of the Jordanian banking sector and its availability and the prevailing pattern in the Jordanian banking sector. The results of the study showed a positive relationship to the role of organizational commitment in improving the performance of employees in the Jordanian banking sector. And that emotional commitment is the most systematic type of organizational commitment to the performance of employees, which is the prevailing pattern in the Jordanian banking sector.

- $\operatorname{In}^{9}$ the study aimed to know the reality of organizational culture in the Palestinian Telecommunications Company and itsimpacton thelevel ofjob performance. The study showed a statistically significant relationship between elements of organizational culture (policies and procedures, rules and standards, behavioral patterns, organizational values, organizational expectations, organizational beliefs, organizational trends) and the level of performance. And that workers need to develop the level of skills and abilities related to creative and innovative aspects to keep abreast of new changes and developments.

- $\operatorname{In}^{10}$ the study aimed to know the role of organizational culture in improving the performance of Jordanian bank employees. The study showed that there is an effect on the organizational culture components (organizational expectations) in improving the performance of employees in the banking sector.

\section{Research Problem and Study Hypothesis}

The problem of the study is that organizational culture leads to an impact on the quality of banking performance and may leave unsatisfactory results, which may be a problem in achieving quality performance in this vital sector. In this study we try to answer the following question: What is the impact of organizational culture on increasing the quality of banking?

Several sub-questions arise from the main question:

- What is organizational culture and what is its concept?

- What are the types, dimensions and importance of organizational culture? 
- What is the banking work, its types and areas, and what is its importance?

- What is the quality of banking work and how can it be measured?

The main hypothesis of this work is given by:

- There is a positive relationship between the culture of the organization that encourages creativity and innovation and improves the quality of work.

- There is an impact of prevailing cultural values on increasing the quality of banking.

\section{Research Objectives}

This study aims to achieve the following objectives:

- Highlighting the nature, types, dimensions and importance of organizational culture ${ }^{11}$.

- Statement of the effects of organizational culture on the quality of banking performance and how to measure them by reviewing some of the books and scientists of management science and human behavior models in this area.

- Statement of the results of the field study conducted on the staff of banks to measure the relationship between organizational culture variables and the quality of banking performance.

- Suggest some appropriate recommendations to contribute to the provision of solutions to overcome some behavioral problems in addition to some suggestions that may establish rules of organizational culture that can support the competitiveness of the economic institution.

- Contribute to the study of cultural obstacles that limit the achievement of distinct performance.

- Show the most important results obtained through the field study and identify the proposals that address the problem of study.

\section{Motivation and Importance of Study}

The importance of this study comes from the need to identify the concept of organizational culture that banks should pay attention to as an effective influence on the quality of banking performance. The theme of the culture of the organization is one of the most important subjects in the field of business management because cultural dimensions affect the organizational behavior and performance of individuals, which is reflected in their positions, motivation and awareness, which helps the organization in dealing with internal and external pressures. Organizational culture is the primary engine of energy and capacity. It primarily affects performance, high productivity and high quality due to the choice of methods, modes and methods of effective movement $\frac{12}{}$.

By following the situation of many institutions with problems, the problem is the spread of many irresponsible behaviors and practices. Is the product of cultural values borne by individuals? Hence the importance of this study is that the management must pay great attention to the quality of performance. This study attempts to shed light on the organizational culture and its effect on the quality of banking work.

\section{Methodology of the Study and Subject Location Limitation}

The various limitations of this study are given as follows:

- Objective limits: The organizational culture and its impact on the quality of banking work.

- Spatial limits: Sudan - Faisal Islamic Bank, Savings Bank and Social Development.

- Time limits: Year 2018.

The two descriptive and analytical methods based on extrapolation, extraction, analysis, linking and treatment were used in the study related to the subject of the study. The analytical descriptive approach was used to illustrate the actual change of the independent variable /organizational culture and to observe the results and effects of this change on the dependent variable/quality of banking $\underline{13}$.

The Community and Sample Search are given by:

- Research community: Employees of Faisal Islamic Bank Branch of Buildings and Savings Bank and Social Development Branch Khartoum South - Sudan.

- The total number of employees in Faisal Islamic Bank Branch Buildings (30) and the number of employees in the Savings Bank and Social Development Branch Khartoum South (27) to be the total sample (57) individuals. 
After determining the objectives of the research, a questionnaire was designed using previous studies. The questionnaire may consist of (20) paragraphs, which included three axes, the first axis (5) paragraphs, the second axis (5) paragraphs, the third axis (10) paragraphs.

\section{Presentation and Discussion of the Results of the Hypotheses of the Study}

\subsection{Results of the First Hypothesis}

The first hypothesis states:

There is a positive relationship between the cultures of the organizations that encourages creativity and innovation and improve the quality of work

To test the existence of statistically significant differences among the respondents, the Kay square test was used to denote the differences between the answers to each hypothesis. Table 1 summarizes the results of the Kay box test for these terms:

From the table above we find that:

The potential value of the term (1) is less than the specified level of $5 \%$. This means that there are statistically significant differences between the responses of individuals in favor of those who agree that there is a tendency among employees to enhance their abilities and skills for the ability to innovate, the work.

The potential value of the term (2) is less than the specified level of $5 \%$. This means that there are statistically significant differences between the responses of individuals in favor of those who agree that there is a clear tendency by the institution to develop the individual's career path so that he can cope with developments and changes new.

Table 1. The results of the Kay box test for these terms

\begin{tabular}{|c|c|c|c|c|c|}
\hline $\begin{array}{l}\text { Explain the } \\
\text { direction } \\
\text { of the } \\
\text { respondents }\end{array}$ & $\begin{array}{l}\text { Sig } \\
\text { Value }\end{array}$ & Average & $\begin{array}{c}\text { The value of } \\
\text { the square } \\
\text { KAI }\end{array}$ & $\begin{array}{l}\text { Freedom } \\
\text { Degree }\end{array}$ & Term \\
\hline Agree & 0.000 & 2 & 15.47 & 2 & $\begin{array}{l}\text { There is a tendency among employees to enhance their abilities } \\
\text { and skills for the ability to innovate, innovate and develop } \\
\text { business systems. }\end{array}$ \\
\hline Agree & 0.000 & 2 & 26.29 & 3 & $\begin{array}{l}\text { There is a clear tendency by the institution to develop the } \\
\text { career path of the individual to be able to keep abreast of new } \\
\text { developments and changes. }\end{array}$ \\
\hline Strongly agree & 0.002 & 2 & 15.21 & 3 & $\begin{array}{l}\text { Senior management is constantly engaged in the process of } \\
\text { institutional development in order to enhance the competitive } \\
\text { position of the institution. }\end{array}$ \\
\hline Agree & 0.000 & 2 & 26.72 & 3 & $\begin{array}{l}\text { Employees tend to establish good working relationships with } \\
\text { their superiors to achieve harmony and harmony, which will } \\
\text { help further progress and achievement. }\end{array}$ \\
\hline Strong agree & 0.001 & 2 & 17.32 & 3 & $\begin{array}{l}\text { The senior management continuously provides the latest } \\
\text { computerized systems and advanced technologies and devices } \\
\text { in order to achieve the required efficiency and speed. }\end{array}$ \\
\hline Agree & 0.000 & 2 & 22.37 & 3 & $\begin{array}{l}\text { The Foundation encourages the continuation of behavior that } \\
\text { suits the beliefs of our. }\end{array}$ \\
\hline Agree & 0.000 & 2 & 35.72 & 4 & $\begin{array}{l}\text { Senior management seeks to establish a democratic approach } \\
\text { between administrative levels. }\end{array}$ \\
\hline Agree & 0.003 & 2 & 16.25 & 4 & Individuals agree in their view of organizational behavior. \\
\hline Strong agree & 0.012 & 2 & 11.00 & 3 & $\begin{array}{l}\text { The Foundation encourages initiative, creativity, and creativity } \\
\text { and the promising ways for a better tomorrow. }\end{array}$ \\
\hline Agree & 0.000 & 2 & 20.83 & 3 & $\begin{array}{l}\text { The Foundation's management seeks to keep pace with the } \\
\text { scientific development of its employees. }\end{array}$ \\
\hline Agree & 0.000 & 2 & 356.09 & 4 & \\
\hline
\end{tabular}


The potential value of the phrase (0.002) is less than the specified level of significance (5\%), which means that there are statistically significant differences between the responses of individuals in favor of those who strongly agree that senior management is constantly undertaking the process of institutional development in order to enhance the competitive position of the institution.

The potential value of the phrase (4) is less than the specified level of $5 \%$. This means that there are statistically significant differences between the responses of individuals in favor of those who agree employees tend to establish good working relationships with their supervisors to achieve harmony and compatibility for further progress and achievement.

The potential value of the phrase $5(0.001)$ is less than the specified level of significance (5\%) which means that there are statistically significant differences between the responses of individuals in favor of those who strongly agree that senior management continuously provides the latest computerized systems and the speed required

The potential value of the phrase (6000) is less than the specified level of significance (5\%), which means that there are statistically significant differences between the responses of individuals in favor of those who agree to encourage the institution to continue the appropriate behavior of our community beliefs.

The potential value of the phrase (7) is less than the specified level of significance (5\%). This means that there are statistically significant differences between the responses of individuals in favor of those who agree on the administration seeks to consolidate the democratic approach between administrative levels

The probability value of the expression $8(0.003)$ is less than the specified level of significance (5\%). This means that there are statistically significant differences between the responses of individuals in favor of those who agree that individuals agree in their view of organizational behavior.

The potential value of the expression 9 (0.012) is less than the specified level of significance (5\%), which means that there are statistically significant differences between the responses of individuals in favor of those who strongly agree on the institution encourages initiative, creativity and promising ways towards a better tomorrow.

The potential value of the expression 10 (0.000) is less than the specified level of significance (5\%), which means that there are statistically significant differences between the responses of individuals in favor of those who agree the management of the institution seeks to keep pace with the scientific development of its employees.

The number of squares in the sample (0.00) indicates that there are statistically significant differences at the level of significance (5\%) between Answer all answers to the hypothesis.

We conclude from the above that the hypothesis of the study, which states that: There is positive relationships between the culture of the organization that promotes creativity and innovation and improve the quality of work were achieved second.

\subsection{Results of the Second Hypothesis}

The second hypothesis states that the cultural values prevailing in the organization have an impact on the quality of work to test for statistically significant differences among the respondents, KAI for these phrases.

From Table 2 we find that:

The potential value of the phrase (0.047) is less than the specified level of significance (5\%), which means that there are statistically significant differences between the responses of individuals in favor of those who strongly agree on doing the work required of me in a good way.

The potential value of the term (2) is less than the specified level of significance (5\%), which means that there are statistically significant differences between the responses of individuals in favor of those who strongly agree to make the necessary effort to accomplish my work on time.

The potential value of the phrase $3(0.000)$ is less than the specified level of the moral (5\%). This means that there are statistically significant differences between the responses of individuals in favor of those who strongly agree on there is knowledge and knowledge of the nature of the work entrusted to me.

The potential value of the phrase (4) is less than the specified level of significance (5\%). There are statistically significant differences between the responses of individuals in favor of those who strongly agree to abide by instructions and procedures when implementing my work.

The potential value of the phrase (5) is less than the specified level of significance (5\%), which means that there are statistically significant differences between the responses of individuals in favor of those who strongly 
Table 2. The results of the KAI box test for these terms

\begin{tabular}{|l|c|c|c|c|l|}
\hline $\begin{array}{c}\text { Explain the } \\
\text { direction } \\
\text { of the } \\
\text { respondents }\end{array}$ & $\begin{array}{c}\text { Sig } \\
\text { Value }\end{array}$ & Average & $\begin{array}{c}\text { KAI } \\
\text { Square } \\
\text { Value }\end{array}$ & $\begin{array}{c}\text { Freedom } \\
\text { degree }\end{array}$ & \multicolumn{1}{|c|}{ Term } \\
\hline Strong agree & 0.047 & 1 & 3.95 & 1 & I do the work that is required of me in a good way. \\
\hline Strong agree & 0.000 & 1 & 24.11 & 2 & Make the effort to complete the work on time. \\
\hline Strong agree & 0.000 & 1 & 47.91 & 3 & $\begin{array}{l}\text { There is knowledge and familiarity with the nature of the work } \\
\text { entrusted to me. }\end{array}$ \\
\hline Strong agree & 0.000 & 1 & 26.00 & 2 & I abide by the instructions and procedures in carrying out my work. \\
\hline Strong agree & 0.000 & 1 & 50.16 & 3 & I coordinate with others in accomplishing my work. \\
\hline Strong agree & 0.000 & 1 & 82.56 & 4 & $\begin{array}{l}\text { There is an ongoing audit, follow-up and guidance from the } \\
\text { supervisors of the achievement. }\end{array}$ \\
\hline Strong agree & 0.000 & 1 & 68.70 & 4 & Be a better performer through teamwork. \\
\hline Strong agree & 0.000 & 1 & 30.51 & 3 & $\begin{array}{l}\text { I participate in making decisions and this helps improve my } \\
\text { performance. }\end{array}$ \\
\hline Strong agree & 0.000 & 1 & 26.00 & 2 & I have good relations with colleagues and bosses. \\
\hline Strong agree & 0.000 & 1 & 38.32 & 2 & Improving your performance contributes to better work quality. \\
\hline Strong agree & 0.000 & 1 & 776.40 & 4 & \\
\hline
\end{tabular}

agree to coordinate with others in accomplishing the work I do.

The potential value of the phrase (6000) is less than the specified level of $5 \%$. This means that there are statistically significant differences between the responses of individuals in favor of those who strongly agree on there is continuous audit and follow-up by the supervisors to complete our business.

The potential value of the phrase (7) is less than the specified level of significance (5\%), which means that there are statistically significant differences between the responses of individuals in favor of those who strongly agree on better performance through collective action.

The probability value of the expression $8(0.000)$ is less than the specified level of significance (5\%), which means that there are statistically significant differences between the answers of the respondents and those who strongly agree to participate in decision making and this helps improve my performance.

The probability value of the expression $9(0.000)$ is less than the specified level of significance (5\%), which means that there are statistically significant differences between the responses of individuals in favor of those who strongly agree on I have good relations with colleagues and presidents.

The potential value of the term $10(0.000)$ is less than the specified level of significance (5\%) which means that there are statistically significant differences between the responses of individuals in favor of those who strongly agree on improving your performance contributes to improving the quality of work.

The value of the square of KAI to indicate the differences between the approved and non-approved answers to all the hypothesis statements (776.40) with freedom degree (4) and the error value allowed in the sample (0.00), indicating that there are statistically significant differences at the level of (5\%) on all hypotheses.

From the above, we conclude that the hypothesis of the study, which states that: There is an impact on the cultural values prevailing in the organization on the increase in the quality of work has been achieved in the first place.

\begin{tabular}{|l|c|}
\hline $\begin{array}{l}\text { There is a tendency among employees to enhance their abilities and skills for the ability to } \\
\text { innovate, innovate and develop business systems. }\end{array}$ & $\begin{array}{c}\text { Hypothesis } 1 \\
\text { There is a positive } \\
\text { relationship Between the } \\
\begin{array}{ll}\text { There is a clear tendency by the institution to develop the career path of the individual to be able to } \\
\text { keep abreast of new developments and changes. }\end{array}\end{array}$ \\
$\begin{array}{l}\text { Senior management is constantly engaged in the process of institutional development in order to } \\
\text { enhance the competitive position of the institution. }\end{array}$ & $\begin{array}{c}\text { Innovation and improving } \\
\text { work quality }\end{array}$ \\
\hline
\end{tabular}


Employees are moving towards establishing good working relationships with their superiors to achieve harmony and harmony, which will help further progress and achievement.

The senior management continuously provides the latest computerized systems and advanced technologies and devices to achieve business efficiency and speed required.

The Foundation encourages the continuation of behavior that suits the beliefs of our society.

The senior management seeks to consolidate the democratic approach between all administrative levels.

Individuals agree in their view of organizational behavior of the institution.

The Foundation encourages initiative, creativity and creativity and the promising ways for a better tomorrow.

The Foundation's management seeks to keep pace with the scientific development of its employees.

There is a positive relationship between the culture of the organization that encourages creativity and innovation and improve the quality of work achieved second degree.

I do the jobs that are required of me in a good way.

I do my best to accomplish my work on time.

There is knowledge and familiarity with the nature of the work entrusted to me.

Observe instructions and procedures when implementing my work.

I coordinate with others in accomplishing the work I do.

There is an ongoing audit, follow-up and guidance by supervisors to accomplish our work.

My performance is better through teamwork.

I participate in making decisions and this helps improve my performance.

I have good relations with colleagues and bosses.

Improving your performance contributes to better work quality.

There is an impact on the cultural values prevailing in the organization to increase the quality of work achieved in the first place.

\section{Conclusion}

Organizational culture consists of three main aspects: Concrete phenomena-values-basic assumptions. Organizational culture consists of organizational values, organizational beliefs, organizational expectations and organizational norms. The organizational culture includes several types: Culture of time, culture of commitment, Intention, TQM culture, culture of quality circles.

The quality of banking services is a measure of the level of service provided to customers to meet their expectations in keeping up with the latest developments in banking technology. There are dimensions to measure and improve the quality of banking work: Reliability, responsiveness, access, communication, efficiency, credibility, courtesy, understanding, safety and financial equipment.

The important achieved results indicate the following important notes:

The cultural values prevailing in the organization have influenced the quality of the work primarily achieved.
There is a positive relationship between the culture of the organization that encourages creativity and innovation and improves the quality of work achieved second degree.

The senior management continuously undertakes the process of institutional development in order to enhance the competitive position of the institution.

The senior management continuously provides the latest computerized systems and advanced technologies and devices in order to achieve the required efficiency and speed.

The Foundation encourages initiative, creation, creativity and promising ways for a better tomorrow.

There are good working relationships with colleagues and heads in the study sector.

The participation of staff in the decision-making processes in the study sector.

On other hand, we recommend the following important points:

The need to take care of organizational culture factors and development, through training and motivation for 
innovation to have a positive impact on the quality of banking work.

The importance of the attention of senior management to broadcast and disseminate the organizational culture among employees.

The need to recognize that organizational culture affects the performance of the organization and the performance of workers directly and indirectly, it is necessarily necessary to consolidate and strengthen.

Work on the continuous improvement of the audits and follow-up and guidance of the employees by supervisors to do business with high quality.

To activate the collective workshops because of their important role in achieving the quality of performance.

The management of the institution to increase interest in the scientific development of its employees and always strive to improve their performance through training and continuing rehabilitation.

Employees must adhere to the right approach and establish the rules of organizational culture based on quality and consistency in their perception and organizational behavior within the institution.

\section{References}

1. Dwivedi RK. Organizational culture and performance. New Delhi, India: M.D. Publications Pvt. Ltd; 1995. p. 5.

2. Inceoglu I. Organizational culture, team climate and workplace bullying and team effectiveness: An empirical study on their relationship. Wissenschen: Herbert Utz Verlag; 2002. p. 16.

3. Clodi DR. Leadership and organizational culture: A multistep program for success. Author House: Bloomington; 2013. p. 35.
4. Dakhil HBM, Al Anzan SBZ. The reality of organizational culture and its relationship to the administrative empowerment of women leaders in government ministries in the Kingdom of Saudi Arabia. 2016.

5. Juma K. The role of the culture of the institution in improving the performance of human resources in the economic institution case study (EN.I.CA.B). Biskra, Algeria: Mohammed Khaydar University; 2015.

6. Siddiqui A. The impact of organizational culture on human resource performance - A case study of a sample of small and medium enterprises in the State of Ouargla, Qasidi University, Marabah-Ouargla. 2013.

7. Ali ND. The role of organizational culture in enhancing organizational commitment. Exploratory Study in Karbala University. Journal of Administration and Economics. 2016; 2(7).

8. Issa AMB, Abazid RA. The role of regulatory commitment in improving the performance of employees in the Jordanian Banking Sector. Dirasat Journal, Administrative Sciences. 2014. p. 41.

9. Akasha AA. The impact of organizational culture on the level of functional performance in Palestine - An applied study on the telecommunication company paltel. Gaza: Islamic University; 2008.

10. Alnsour MM. The role of organizational culture in improving the performance of employees in the Jordanian Banking Sector. Journal of the Islamic University for Economic and Administrative Studies, Scientific Research and Graduate Studies. Gaza: Islamic University, Palestine; 2012.

11. Schein EH. Organizational culture and leadership. John Wiley and Sons. 2017. p. 42-3.

12. Al-Bakri F. Public relations and changing the culture of organizations. Cairo: World Books; 2014.

13. Tariq Abdel-Rauf A. Arab group for training and publishing. Cairo. 2014. p. 232-3. 